\title{
Biology Teachers' Perception of Multiple Choice Questions (MCQs) in the G.C.E Advanced Level Biology and Students' Academic Performance in the South West Region of Cameroon
}

\author{
Lydia Enanga Awo, Nyukechen Henry Tambe, Grace Mbepwo Fongod and Tambe Joseph Orock \\ University of Buea \\ South West, Region \\ Cameroon
}

\begin{abstract}
The study "Biology Teachers' Perception of MCQs in the GCE Advanced Level Biology and Students' Academic Performance in the South West Region" was carried out to examine the views of Advanced Level Biology teachers on the use of MCQs, an innovation in the GCE Examination since June, 2009. The study made use of the survey design. The research questions were as follows: (1) To what extent do Biology teachers master the construction of MCQs? (2) To what extent does the use of MCQs provide Biology teachers with a better means for assessing student learning than the use of short-answer structural questions? (3) How is the use of MCQs in Advanced Level Biology helpful in the attainment of instructional objectives? (4) What constraints do Biology teachers experience in constructing MCQs? (5) To what extent do Biology teachers feel adequately involved in the making of decisions with respect to the use of MCQs? The instrument used to collect the data was the questionnaire made up of 37 close-ended questions. A sample of 183 Advanced Level Biology teachers in the Fako, Manyu and Meme Divisions of the South West Region took part in the study. Out of the 183 copies of the questionnaire administered, 183 were returned, giving a percentage returned of 100\%. Data were analyzed descriptively using simple and relative frequencies and percentages and also inferentially using the chi square. The results showed that Biology teachers have a positive perception of the use of MCQs. They have a mastery of the construction of MCQs, MCQs is better than short answer structural questions, MCQs at the Advanced level Biology is helpful in the attainment of instructional objectives, they do not experience constraints in constructing MCQs, and Biology Teachers partake in decision-making on matters that concern MCQs. This positive perception influences the students' academic performance positively as seen in the steady rise of Advanced Level GCE Biology results from 2009 which is the year of inception of MCQs in the GCE Board examination to 2016. The sudden drop in the year 2017 is due to the unrest atmosphere witnessed in the English speaking Region of Cameroon as gotten from some purposively selected schools in the South West Region as shown in the appendix.
\end{abstract}

Key Words: Perception, Multiple choices (MCQs), Advanced Level Biology, Academic Performance.

\section{INTRODUCTION}

Many school systems and educators are responding to calls of reform in assessment by proposing a variety of alternatives to standardized testing. These proposals are diverse, controversial and apprehensive, especially to the teachers who are the implementers of the change. In Cameroon, Law no 98/004 of 14 April 1998 section 39 states that 'Teachers shall be bound to teach, educate, provide educational guidance, promote the quest for scientific knowledge, carry out assessment and be of moral rectitude.

Teaching according to Tambo (2003), refers to all activities done before, during and after interaction with learners in order to enable learning to take place[1]. The purpose of teaching therefore is to improve the knowledge or skills and attitude of learners. It is therefore the concern of teachers to find out if learning actually takes place before, during and after teaching. It is in this light that Smith and Ragan (2005) and Mbua (2003), look at assessment as one of the roles of teachers [2-3].

One of the ways of assessing learners is by the use of pencil-and-paper tests or written tests. Tambo (2003) categorized written tests into types: objective tests and essay tests with multiple-choice questions (MCQs) being one form of objective tests. MCQ is a 
type of test in which a direct question or incomplete statement is presented and a number of responses are given [1]. The test taker is asked to choose for each item, the correct or best answer from the response options.

Airasian (1997) looks at assessment as the collection, synthesis and interpretation of information to aid the teacher in decision making [4]. Tambo (2003) holds that assessment refers to the process of developing, administering and marking (scoring) tests and other assessment instruments for the purpose of finding out if learning took place during teaching. It is therefore obvious that any meaningful conceptualization of the teaching process has to recognize the interdependence between teaching and assessment. Section 37 of Law number 98/004 of April 1998 says that teachers shall be the principal guarantor of the quality of education. Section II of law number 98/004 of 14 April 1998 emphasizes that the state shall formulate and implement educational policy, with the assistance of Regional and Local authorities, families as well as public and private institutions. Ornsteins and Hunkins (2009) look at the place of the Board of Education in Curriculum Development [5]. According to them, many state boards of education make formal recommendations and issue guidelines regarding what the Curriculum should contain and how it should be organized. The Ministerial Decision 'Regulations and Syllabuses for general Education Subjects (2007) published by the CGCEB indicated that MCQs was to be in paper one of all subjects at both the Ordinary and the Advanced level physics paper one has been multiple-choice questions even before the CGCEB could come up with this reform [6]. However, this innovation was not completely receptive by all stakeholders. Biology Teachers see the policy through different lenses due to the fact that of all types of objectives test questions, MCQs are the most difficult and time consuming questions to design. In addition, it requires the teachers to re-orient their teaching towards complete syllabus coverage and mastery of programme content. It is against this backdrop that this researcher sought to find out how Biology teachers perceive the use of MCQs in GCE Advanced level Biology and Students' academic performance in the South West Region of Cameroon. This chapter shall comprise the background of the study, the statement of the problem, the purpose of the study, the objectives of the study, the research questions, the hypotheses, the significance of the study, the scope of the study and the definition of operational terms.

\section{THEORETICAL AND CONCEPTUAL FRAME WORK}

The two factor theory, Goal setting theory, Expectancy theory, Cognitive theory and the Symbolic interaction theory have been used to guide this study

The two-factor or motivation-hygiene theory was propounded by Hezberg, Mausner, and Synderman (1959) is based on the premises that the work environment comprises of two-factors: the Satisfiers known as the motivating factors and the dissatisfiers known as the hygiene factors [7]. According to them, motivating factors of the work environment include: achievement, responsibility, recognition, advancement, possibility of growth, and that the hygiene factors include: status, interpersonal relations, technical supervision, school policy and administration, personal life, job security, working condition, and salary. if a Biology teacher is recognized as a key actor in implementing the MCQ and is given increased responsibility for making decisions about the use of MCQs in GCE Advanced Level Biology, and is encouraged to modify her/his teaching/assessment strategy with respect to the use of MCQs, then she/he will tend to put more time and energy.

2.1 Goal-Setting Theory: Locke and Latham, (1990), as cited in Mbua, (2003), are generally recognized for the development and renewed interest in this theory it stipulates that, the intentions to achieve a goal constitute the primary motivating force behind work behavior[8,3]. The extent to which biology teachers are motivated with respect to the use of MCQS, has an effect on the students' academic performance at the biology advanced level.

2.2 Expectancy Theory: This theory was originally proposed by Vroom [9]. It is based on three concepts: Valence, Instrumentality, and Expectancy, reason why the theory is also referred to as Valence-Instrumentality-Expectancy (VIE) theory. Valence: This refers to the perceived positive or negative worth or attractiveness of potential outcomes, rewards, or incentives for working in an organization.

2.3 Instrumentality: This refers to the perceived relationship between incentive and a given level of performance.

2.4 Expectancy: It refers to the subjective probability that a given effort will yield a specified performance level.

2.5 Cognitive Theory: This theory founded by George Miller in the year 1956 and evolved through Brunner (1960) and Neisser (1967), centres on the premises that the mental processes of people is of prime significance in determining social actions. These mental processes relate to an individual's perception, memory, judgment, problem solving and decision making capabilities.

2.6 Symbolic Interaction Theory: This theory was founded by Max Weber in the year 1951.The theory gives primacy to the role of interactions between individuals and their societies in the cognitive process. Michener, DeLamater and Myers (op cit: 14) point out that "the basic premises of symbolic interactions is that human nature and social order are product of symbolic communication among people. 
The perception of Biology teachers with respect to the use of MCQs probably has to take into account the level at which educational objectives can be classified and measured, the developmental stage of the learners, and the nature of instruction in order to meet the needs of MCQs. Behavioural approach to learning has resulted to learning types such as classical conditioning. This began with an accidental discovery by Ivan Pavlov. Although Pavlov worked with dogs, classical conditioning can also be used to understand a wide variety of issues concerning human behavior. Classical conditioning is a form of learning in which a previously neutral stimulus (NS) is paired with an unconditioned stimulus (UCS) to elicit a conditioned response (CR) that is identical or similar to the unconditioned response (UCR), (Lahey), [10]. Biology teachers had been using short-answer structural questions in paper one Biology before the decision of the CGCEB to change the format. As such, the minds of the teachers ${ }^{\text {ee }}$ were already conditioned on the type of questions to set with respect to Biology paper one. The degree to which the process of extinction takes place in the minds of these teachers, may consequently effect their perception on the use of MCQs in O/L Biology. Considering the fact that assessment and evaluation play very important roles in the teaching-learning process, the way teachers perceive the use of MCQs as one of the ways of assessing the learners, is also very important. According to Ngoh and Mbangwana (2001)[11], the term evaluation is synonymous to tests, examination, assessment and even measurement. These terms are often used interchangeably because all of them aim at measuring educational outcomes and to measure students ${ }^{\text {ce }}$ performances or progress. According to Tambo (2003), multiple choice questions are a type of test in which a direct question or incomplete statement is presented and a number of possible responses are given. The test taker is asked to choose for each item, the one correct or best answer from suggested alternatives. The items of a multiple choice are often colloquially referred to as „,questions, ${ }^{\text {"e }}$ but this is a misnomer, owing to the fact that many items are not phrased as questions. For example, they can be presented as complete statements or mathematical equations. Thus the more general term ,item ${ }^{\text {ee }}$ is the most appropriate label. Anuchem (2010)[12] describes four types of MCQs, namely; a. The simple multiple choice questions; in which the stem is a question, statement or incomplete statement. The test taker is expected to choose amongst the options, one answer that best fits the stem. $b$. The classification question; in which a series of MCQ are set using identical responses labeled A, B, C, D or E. Each response may be used once, more than once, or not at all. c. The multiple completion questions; this type of questions use a stem together with four responses numbered 1-4. One or more of the responses are correct. The test taker is required to decide which of the response ( $\mathrm{s}$ ) is (are) best, then choose the letter corresponding to the best answer using a given code or direction. d. Assertion and reason; each question consists of a statement in the left-hand column, followed by a statement in the right-hand column. The candidate is expected to decide whether each of the statements is true or false. Then choose the letter corresponding to the correct answer using a given code or directions. Tambo (2003) says the most familiar and less complicated types are;

- The question variety

- The correct or best answer variety

- The incorrect or worst answer variety

- The multiple-response variety

- The common principle or most inclusive variety

- The most dissimilar-answer variety, and

- The combined response variety.

\section{METHODOLOGY}

3.1 Research Design: The design adopted for this study is the survey design. According to Nworgu (1992), a survey design is generally considered as one in which a group of individuals is studied by collecting and analyzing data from a selection of a few, which in turn is considered to be a representation of the entire group [13]. This type of research design is characterized by lack of control, and the researcher being involved in this kind of study, was interested in identifying and describing how sample subjects felt at one point in time, without any attempt to control or manipulate them.

3.2 Area of study: This study was carried out in one of the English speaking Regions of the Republic of Cameroon- the South West. The South West Region is divided into six Divisions: Fako, Meme, Ndian, Kupe Manenguba, Lebialem, and Manyu. Each of these Divisions is subdivided into subdivisions. This Region has some important geographical features such as the Mount Cameroon, which is found in Buea, the capital of the Region. One of the important towns in this Region is the sea side resort town of Limbe, with its beaches. The population of the South West Region is heterogeneous, made up of people from all over Cameroon and some neighboring countries like Nigeria and Equatorial Guinea. The Region has the first English-speaking University in Cameroon, the University of Buea. Agriculture and fishing are the key livelihood occupations for the greater rural population. Besides Buea and Limbe, other important towns in this Region include: Kumba, Mamfe, and Tiko. The Region has a 
good number of public, denominational, and lay-private secondary and high schools and colleges. It plays host to higher, secondary and primary education institutions and the Cameroon GCE Board.

3.3 Population of the study: The population of the study consisted of all Biology teachers in Government, lay private and denominational (mission) high schools of the South West Region.

3.4Target Population: Biology Teachers from three Divisions ( Fako, Manyu and Meme) after a purposive sampling constituted the target population of the study.

3.5 Accessible Population: The following schools in the table below were visited in the Fako, Manyu and Meme division and constituted the accessible population.

Table 1: Names of schools visited in Fako, Manyu and Meme Division of the South West Region

\begin{tabular}{|l|l|l|l|l|l|}
\hline \multicolumn{1}{|c|}{ Fako } & $\begin{array}{c}\text { No of } \\
\text { Teachers }\end{array}$ & \multicolumn{1}{c|}{ Manyu } & $\begin{array}{c}\text { No of } \\
\text { Teachers }\end{array}$ & \multicolumn{1}{c|}{ Meme of } \\
Teachers
\end{tabular}

\subsection{Sample Size}

The sample size was made up of some selected 183 Government, Lay Private and Denominational Biology teachers who were purposively selected from some Secondary High Schools from, Fako, Manyu, and Meme Division of the South West Region.

Table 2 Distribution of Sample

\begin{tabular}{|c|c|c|}
\hline Division & $\begin{array}{c}\text { Number of } \\
\text { Teachers }\end{array}$ & $\begin{array}{c}\text { Number of teachers selected } \\
\text { (sample Size) }\end{array}$ \\
\hline Fako & 150 & 109 \\
\hline Manyu & 85 & 36 \\
\hline
\end{tabular}


International Journal of Advances in Scientific Research and Engineering (ijasre), Vol 5 (11), November-2019

\begin{tabular}{|c|c|c|}
\hline Meme & 65 & 38 \\
\hline Total & $\mathbf{3 0 0}$ & $\mathbf{1 8 3}$ \\
\hline
\end{tabular}

\subsection{Sampling Techniques}

This study employed a Triangulation of sampling techniques, that is purposive sampling techniques to identify the participants who had the information and simple random sampling was then conducted to select who to participate. Purposive sampling was used in identifying the participant because the researcher wanted to study the performance of only Advanced Level Biology Students. Simple random sampling was used in order to avoid bias and to ensure that each Biology teacher from a selected school had an equal chance of being selected. According to Amin (2005)[14] randomization is effective in creating equivalent representative groups that are essentially the same on all relevant variables thought of by the researcher.

\section{INSTRUMENTATION}

The instrument used in this study is the questionnaire and documentary analysis. The questionnaire was formulated by the researcher in consultation with the Supervisor who went through it item by item. The questionnaire was used for data collection because the population was literate and large and time for collecting data was limited. The researcher developed closed ended questions because they are easy to fill, save time and keep the respondents focused on the subject. At the beginning of the questionnaire, there was an introductory note stating the research topic and the purpose of the questionnaire. In this note the researcher ended by thanking the respondents for the time spared to provide responses and promised them that their information was confidential and would be used strictly for research purposes. The questionnaire was divided into sections: A, B, C, D, E, and F. Section A with two items was on the demographic profile of the respondent. Section B to F contained items that are directed towards answering of the specific research questions as follows: Section B with ten items was on specific research question one. Section C of nine items was on specific research Question two. Section D with ten items was on specific research question three. Section $E$ with five items was on specific research question four, while section $F$ with three items was on specific research question five .The items were close-ended, with Likert-type response options ranging from strongly agree (SA) to Undecided (U) . The Likert-type close - ended items were used because of ease of responding.

\subsection{Documented Analysis}

Secondary sources like the internet sources and documentaries (GCE Results and policies) were used to obtain existing literature about the topic and analysis of the field-collected data.

\subsection{Validity and Reliability of Research instruments}

Validity of the questionnaire was obtained by presenting it to at least two professional People, including the Researcher's Supervisor for necessary scrutiny and corrections because according to Amin (2005)[14], content and construct validity is determined by expert judgment. The final version of the questionnaire was pretested among some classmates and Biology teachers. Further validation of the instrument was done as the Researcher carried out a pilot study to 15 Biology teachers in Tiko sub-division of the South West Region twice within two weeks. After the pilot study, the questionnaire was confirmed by the Supervisor as valid.

Reliability of the instruments was obtained by using the test -retest reliability to measure the consistency in opinion

\subsection{Data Collection}

The Researcher visited some selected schools in the South West Region. In GHS Buea, BGS Molyko, Saint Joseph College Sasse, BHS Buea, Summerset Bilingual College Buea, GHS Limbe, GBHS Limbe, Saker Baptist College Limbe, GHS Bonjongo and , GBHS Kumba. She met and introduced herself to the Principal. The Principal then gave her the opportunity to talk to the Head of the Department for Biology (Advanced Level)who then introduced her to the Biology teachers for Advanced Level Biology. The Researcher administered the questionnaire to the respondents on the spot. Some of the respondents completed the questionnaire on the spot and returned it to her while others asked to pass and collect the completed questionnaire on a later date. Meanwhile in GHS Mamfe, GHS Akwaya, GHS Kembong, GBHS Mundemba, GHS Konye and GBHS Tombel, the questionnaires were administered by her friends who went through the same procedure and later forwarded the questionnaire back to the Researcher in Buea.

The GCE Advanced Level Biology results of some selected schools in the South West Region were collected from the Cameroon GCE Board, specific schools and web sites from the year 2009 to 2017 for measuring the students' academic performances. The Researcher started from 2009 because this is the year which the Cameroon GCE Board started administrating multiple choice questions in both the ordinary and advanced level GCE. 
International Journal of Advances in Scientific Research and Engineering (ijasre), Vol 5 (11), November-2019

Table 3: Academic performance in Advanced Level Biology: A Table showing the general GCE Results percentages for Advanced Level Biology from 2009 to 2017.

\begin{tabular}{|l|l|l|l|l|l|l|l|l|l|}
\hline Year & $\mathbf{2 0 1 7}$ & $\mathbf{2 0 1 6}$ & $\mathbf{2 0 1 5}$ & $\mathbf{2 0 1 4}$ & $\mathbf{2 0 1 3}$ & $\mathbf{2 0 1 2}$ & $\mathbf{2 0 1 1}$ & $\mathbf{2 0 1 0}$ & $\mathbf{2 0 0 9}$ \\
\hline Percentage & 35.32 & 69.61 & 69.53 & 66.52 & 64.93 & 63.98 & 60.41 & 55.98 & 43.93 \\
\hline
\end{tabular}

4.4 Questionnaire Return Rate: One hundred and eighty three copies of the questionnaires were administered. The tables below shows the return rate of copies administered.

Table 4 Questionnaire return rate

\begin{tabular}{|c|c|c|c|}
\hline Division & $\mathbf{N}^{\mathbf{0}}$ Administered & $\mathbf{N}^{\mathbf{0}}$ Returned & \% Returned \\
\hline Fako & 109 & 109 & 100 \\
\hline Manyu & 36 & 36 & 100 \\
\hline Meme & 38 & 38 & 100 \\
\hline Total & $\mathbf{1 8 3}$ & $\mathbf{1 8 3}$ & $\mathbf{1 0 0}$ \\
\hline
\end{tabular}

The table above shows that out of the 183 copies of the questionnaire administered, 183 were returned, giving a percentage returned of $100 \%$.

4.5 Method of Data Analysis: Data from questionnaires was compiled, sorted, edited, and classified into sheets. The Likert-type items were analyzed descriptively using simple and relative frequencies and percentages in search of trends.

For inferential statistics, the chi-square $\left(\mathbf{x}^{2}\right)$ was used to test whether or not opinions on the issues raised in the questionnaire depended on the teacher's working Division.

Findings The findings of this research show that:

A Biology Teachers mastery of the construction of MCQs affects students' academic performance.

B Biology teachers' belief in the use of MCQs for assessment affects students' academic performance.

C Biology teachers' commitment to the use of MCQs to achieve instructional objectives affects students' academic performance.

D Teachers' constraints involved in constructing MCQs affect students' academic performance.

E Biology Teachers involvement in decision making affects students' academic performance.

\section{CONCLUSION}

The purpose of this study was to examine Biology teachers' perception of MCQs in the GCE Advanced Level Biology and Students' Academic Performance. Findings from this study have identified areas of strength and weakness in the perception of biology teachers in mastering the construction of MCQs, using MCQs as an assessment tool, using MCQs to attain instructional objectives, and involving in decision making in matters that concern MCQs, and how this perception affects students' academic performance. The perception reveals areas which necessitate intensive and urgent capacity building or training to ensure high teacher and students' academic performance. Any nation's woes can emanate from it educational system. Schools are critical to the sustainable development of this country and teachers are uniquely positioned to create, nurture and sustain enabling studying and assessment method/environment for their students. The Ministry of Secondary Education and the GCE Board in Cameroon need to re-think the biology teacher-ship and students' academic performance in the South West Region and institute in-service training, availability of resources and the control of work loads of teachers prior to assuming assessment changes. In the absence of capacity building structures or facilities, most biology teachers learn about MCQs through 'trial and error' approaches (learning from the wrong source) with the potential to hurt the educational sector and the achievement of the students. The perception of Biology teachers on the use of MCQs in Advanced Level Biology will likely become more positive and the students' academic performance will increase even more.

\section{RECOMMENDATIONS}

Based on the findings, the following recommendations were proffered:

\subsection{To Teachers}

1. Teachers should attend seminars especially those that have to do with the construction of MCQs whenever they are organized. 
2. Teachers should make adequate use of human and material resources at their disposal, that have to do with MCQs.

\subsection{To School Administrators}

1. School Administrators should help ensure that their teachers attend seminars whenever they are scheduled.

2. They should motivate Biology teachers to construct and use MCQs by providing them with the necessary didactic materials and/or equipment for the construction and use of MCQs.

\subsection{To Policy Makers}

1. More seminars should be organized on the construction and use of MCQs for both new and old teachers.

2. Biology teachers should be educated on test item analysis, and encouraged to use it each time they construct and use MCQs.

\section{REFERENCES}

1. Tambo, L.I. (2003). Principles and Methods of Teaching. Applications in Cameroon Schools, Limbe: ANUCAM Publishers.

2. Smith,P.L. and Regan, T.J.(2005). Instructional Design. 3rd Edition. USA: John Wiley \& Sons Inc.

3. Mbua, F. N. (2003). Educational Administration: Theory and Practice. Limbe: Design House.

4. Airasian, P.W(1997). Classroom Assessment. USA: McGraw-Hill Companies Inc.

5. Ornstein, A. C. and Hunkins, F.P. (2009). Curriculum Foundations, Principles, and Issues 5th Edition. USA: Pearson Education Inc.

6. CGCE Board. (2010). Results Report. Buea.. Cameroon GCE Board.

7. Herzberg, F.M.B., and Synderman, B. (1959). The Motivation to Work. New York: John Wiley and Sons.

8. Locke, E.A., and Latham, G. P. (1990). A Theory of Goal Setting and Task Perfomance. Englewood Cliffs, NJ: Prentice-Hall.

9. Vroom, V. H. (1964). Work and Motivation. New York: Wiley.

10. Lahey, B. B. (2003). Psychology: An Introduction. 8th Edition. Boston: McGraw Hill Higher Education.

11. Ngoh, N. and Mbangwana, M. (2001). Understanding Examinations: A practical guide to measurement and evaluation of teachers. Yaounde: PUA.

12. Anuchem, L. C. (2010). Multiple Choice Questions (MCQs). Paper Presentation during a South West Chemistry Teachers' Association (SOWECTA) Seminar held at GBHS Muea, Buea , pp 2-4.

13. Nworgu, B.G. (1992). Educational Research: Basic Issues and Methodology.Ibadan: Wisdom Publisher Ltd.

14. Amin, E. M. (2005). Social Science Research. Conception, Methodology and Analysis. Uganda: Makerere University Printery. 